\title{
Interdependence and dynamics of essential services in an extensive risk context: a case study in Montserrat, West Indies
}

\author{
V. L. Sword-Daniels ${ }^{1,2}$, T. Rossetto ${ }^{2}$, T. M. Wilson ${ }^{3}$, and S. Sargeant ${ }^{4}$ \\ ${ }^{1}$ Centre for Urban Sustainability and Resilience, Department of Civil, Environmental and Geomatic Engineering, \\ University College London, London, UK \\ ${ }^{2}$ EPICentre, Department of Civil, Environmental and Geomatic Engineering, University College London, London, UK \\ ${ }^{3}$ Department of Geological Sciences, University of Canterbury, Christchurch, New Zealand \\ ${ }^{4}$ British Geological Survey, Murchison House, West Mains Road, Edinburgh, UK \\ Correspondence to: V. L. Sword-Daniels (victoria.sword-daniels.09@ucl.ac.uk)
}

Received: 13 November 2014 - Published in Nat. Hazards Earth Syst. Sci. Discuss.: 4 February 2015

Accepted: 7 April 2015 - Published: 7 May 2015

\begin{abstract}
The essential services that support urban living are complex and interdependent, and their disruption in disasters directly affects society. Yet there are few empirical studies to inform our understanding of the vulnerabilities and resilience of complex infrastructure systems in disasters.

This research takes a systems thinking approach to explore the dynamic behaviour of a network of essential services, in the presence and absence of volcanic ashfall hazards in Montserrat, West Indies. Adopting a case study methodology and qualitative methods to gather empirical data, we centre the study on the healthcare system and its interconnected network of essential services. We identify different types of relationship between sectors and develop a new interdependence classification system for analysis. Relationships are further categorised by hazard conditions, for use in extensive risk contexts.

During heightened volcanic activity, relationships between systems transform in both number and type: connections increase across the network by $41 \%$, and adapt to increase cooperation and information sharing. Interconnections add capacities to the network, increasing the resilience of prioritised sectors. This in-depth and context-specific approach provides a new methodology for studying the dynamics of infrastructure interdependence in an extensive risk context, and can be adapted for use in other hazard contexts.
\end{abstract}

\section{Introduction}

Infrastructure is critical to supporting modern societies, particularly in urban areas, where large populations create high demand for essential services such as schools, healthcare, energy, water, waste disposal, roads and communications (Platt, 1991). There has been growing recognition that the high degree of dependency between different critical infrastructures pass on disruptions between interconnected sectors, both directly and indirectly, as well as to the economy and society (Platt, 1991; Rinaldi et al., 2001; Chang and Shinozuka, 2004; McDaniels et al., 2008; Chang, 2009; Oh et al., 2010; Pelling, 2002; Santella et al., 2009). For example, loss of power during Hurricane Katrina in 2004 caused failures in telecommunications systems, which further disrupted the organisation of rescue and relief efforts (Santella et al., 2009). In another example, the collapse of the twin towers of the World Trade Center in 2001 ruptured water mains, and impaired firefighting due to falling water pressure at fire hydrants (O'Rourke, 2007). Yet technical understanding of infrastructure interdependencies is still in its early stages (Chang, 2009). In disasters there are few empirical studies of interdependent infrastructure to inform understanding of the vulnerabilities and resilience of a network of connected systems (Santella et al., 2009). Existing empirical studies focus on the vulnerabilities created by interdependencies, and on extreme disaster events. There is sparse empirical study of interdependence in volcanic contexts (Wilson et al., 2012; Sword-Daniels, 2014), and to our knowledge there 
are no studies of the dynamics of infrastructure interdependence in the presence and absence of hazards, or in extensive risk contexts.

The island of Montserrat, West Indies, provides a case study of essential services operating in a long-duration volcanic hazard context (eruption 1995-present), where volcanic ashfall hazards intermittently affect the population in the north of the island. Taking a systems thinking approach, bounded by the geographical extent of the island, we adopt a qualitative case study methodology to explore the dynamics and interdependence of essential services in this extensive volcanic risk context.

We centre this study on the healthcare system as a complex system nested within a network of essential services. Using empirical data, we describe the complex nature of the interrelationships between essential services, from which we develop a new classification system in order to analyse their interdependencies. Then we explore the dynamic transformation of relationships in the presence and absence of volcanic ashfall hazards and interpret how this influences resilience in this context. This provides a novel approach for exploring the complexities of interdependent systems that adds depth to our understanding, and provides a new methodology for studying dynamic infrastructure interdependence. This increases understanding of the characteristics and resilience of a network of complex systems in an extensive risk context.

\section{Background}

In the literature, study of the interdependencies between complex systems is used in critical infrastructure system (CIS) approaches as a way of understanding their resilience (Chang et al., 2007). In order to describe impacts across many different infrastructure systems, interdisciplinary expertise is needed and a large amount of descriptive data is required (Santella et al., 2009). Table top exercises with experts from multiple infrastructures are used, but are expensive (in terms of both time and money) and logistically difficult to organise. As a result, models of interdependent critical infrastructure systems are proposed as tools to aid decisionmaking and to supplement, or even to replace, expert judgement (Santella et al., 2009). Such models account for system dynamics through simple feedback loops, and stocks and flows into the system in order to model the effects of failures across interdependent systems, and to trial interventions. Yet challenges in obtaining data for a variety of different infrastructures, and in disaster events, has resulted in limited validation of such models (Santella et al., 2009).

Empirical studies of CIS interdependencies use case study data from past disaster events, which are derived from hurricane, ice storm and earthquake events (Chang et al., 2007; McDaniels et al., 2008; Oh et al., 2010). These studies predominantly explore interdependent relationships in order to identify impacts of disruption from a hazard, critical points of vulnerability, and ways to manage or reduce risk through decision-making (Oh et al., 2010; McDaniels et al., 2008) and mitigation (Chang et al., 2007). One study provides a framework for understanding the disruption to one infrastructure system (power outage) and the cascading impacts that result across connected infrastructures (Chang et al., 2007). Another study creates decision diagrams for one infrastructure system, considering the impacts on this system from external disruption, but does not consider how this system affects wider society or how multiple infrastructure systems may affect each other (McDaniels et al., 2008). In these studies, considering consequences to one infrastructure system, rather than many infrastructures at once, simplifies the complexity of a disaster. A study that considers several interdependent infrastructure sectors focuses on interdependencies between directly impacted sectors (e.g. buildings, bridges, levees, power, communications, road, oil facilities) and the physical impacts to infrastructure affected by their disruption (e.g. healthcare, food, agriculture, transportation, communication, oil refinery, retail) (Oh et al., 2010). Yet limitations in considering only physical interdependencies between many infrastructure systems, rather than the many other ways in which infrastructure systems communicate, coordinate and interact, results in simplified scenarios for decision-making. In accordance with the epistemological framing of the resilience concept within CIS, resilience is measured by looking at redundancy and restoration of services (Reed et al., 2009; Bruneau et al., 2003). Focus is on the vulnerabilities identified from cascading impacts, and there is little focus on learning and adaptation, or on the social and political dimensions of vulnerability and resilience.

A few disaster and socio-ecological systems studies have identified the importance of adaptation in networks of systems. These show that the number of links between systems increases during periods of reorganisation in crises, as sleeping links become activated to exchange information (Janssen et al., 2006; Kartez, 1984). For example, a study of the response of 26 local governments to the eruption of Mt St Helen's in 1980 finds that adaptive relationships were developed for responding to the disaster. These formed along pre-existing lines of organisational communication and took place entirely at the local level, outside the institutional context of emergency planning at state and federal level (Kartez, 1984). Such studies demonstrate the adaptive capacity of a network and the context-specific nature of the response.

To our knowledge, there are no in-depth empirical studies of essential service interdependence in disasters that account for the complexity of interactions, and the adaptive behaviour of a network of essential services. Cause and effect models are unable to adequately account for non-linear behaviour (Cavallo and Ireland, 2014). As a result, studies of complexity need to be approached through analogy and narratives (Allen, 2008). Further, there has been no consideration of non-extreme disaster events and the effects that smaller, more frequent event types may have on interdepen- 
dent essential services. These effects are likely to be lower impact but more widespread - constituting environments of extensive risk.

Extensive risk is defined as follows:

The widespread risk associated with the exposure of dispersed populations to repeated or persistent hazard conditions of low or moderate intensity, often of a highly localised nature, which can lead to debilitating cumulative disaster impacts" (United Nations International Strategy for Disaster Reduction, 2009b, p. 15-16).

Extensive risk is associated with widespread low-intensity losses that may include a large number of affected people, damage to infrastructure or housing. The 2013 Global Assessment Report on Disaster Risk Reduction finds that in 56 case studies, more than $90 \%$ of local damage to roads, telecommunications, power and water supplies derived from extensive risk (United Nations International Strategy for Disaster Reduction, 2013). In the 2009 sample of case studies, $65 \%$ of all hospital losses in disasters are attributed to extensive risk (United Nations International Strategy for Disaster Reduction, 2009a).

Extensive risk contexts are mainly associated with climate and weather-related hazards, and predominantly, although not exclusively, with localised hazards (United Nations International Strategy for Disaster Reduction, 2013). In volcanic contexts, some volcanic hazards are intensive (high severity, low frequency), such as explosions or pyroclastic flows, and some are extensive (low impact, high frequency), such as ashfalls, gases and acid rain. In long-duration volcanic eruptions (i.e. ongoing for many years e.g. Tungurahua Volcano, Ecuador, 1999-present; and Soufriere Hills Volcano, Montserrat, 1995-present), the frequency and widespread exposure of people and assets to low-impact ashfalls constitute environments of extensive risk. To date, the effects of ongoing volcanic activity (frequent primary ashfalls or windblown remobilisation of ash) on society, or on the essential services that support modern urban living, have been scarcely explored (Tobin and Whiteford, 2004; Wilson et al., 2011; Sword-Daniels, 2014; Sword-Daniels et al., 2011).

Volcanic ashfalls are capable of disrupting or even damaging the essential services upon which society depends (Wilson et al., 2012; Ronan et al., 2000; Blong, 1984). Several eruptions have illustrated the vulnerability of urban areas that receive only a few millimetres or centimetres of volcanic ash. Empirical case studies of volcanic ash impacts have been conducted at the following sites: Soufrière Hills Volcano, Montserrat, West Indies, 2010-2012; Tungurahua Volcano, Ecuador, 2010; Pacaya Volcano, Guatemala, 2010; Reventador Volcano, Ecuador, 2002; Mt. Ruapehu, New Zealand, 1995-1996; and Mt. Hudson, Chile, 1991 (Johnston, 1997; Johnston et al., 2000, 2004; Leonard et al., 2005; Stewart et al., 2006; Sword-Daniels et al., 2011, 2014; Wardman et al., 2012; Wilson et al., 2009, 2010). Ashfall impact studies have included aspects of structural loading, electrical power networks, water and wastewater systems, telecommunications networks, aircraft, land transportation, heating ventilation and air conditioning (HVAC) systems, and laptop computers. Studies have focussed mainly on single ashfall events, and were recently summarised by Wilson et al. (2012).

Ash impacts to complex essential service sectors such as healthcare systems have only recently been explored, through case studies in Montserrat, Guatemala and Ecuador (Sword-Daniels et al., 2011; Wardman et al., 2012; SwordDaniels, 2014). Few studies consider the cascading effects of volcanic impacts across sectors, and there is little empirical knowledge of the interdependent effects of volcanic hazards for essential services and society (Johnston, 1997; Auckland Engineering Lifelines Group, 1999; Wilson et al., 2012; Sword-Daniels, 2014).

\section{Case study context}

Montserrat is a small British overseas territory in the West Indies (Fig. 1). It has a colonial history and a complex dual government system with a British governor (appointed by the UK government) and the locally elected government of Montserrat (GoM). The sudden onset eruption of the Soufrière Hills Volcano began on 18 July 1995 (Sparks and Young, 2002) and large-scale evacuations from inhabited areas closest to the volcano ensued. In 1996 an exclusion zone was established, and the majority of the population, including all the inhabitants of the capital, Plymouth, were permanently relocated further from the volcano (Aspinall et al., 2002), to a little-developed landscape in the north of the island (Clay et al., 1999).

The eruption, which is ongoing at the time of writing, triggered a protracted disaster that has been exacerbated by the dual governance system, large-scale population emigration, and significant economic decline (Clay et al., 1999; Druitt and Kokelaar, 2002; Wisner et al., 2004; Haynes, 2005, 2006; Sword-Daniels et al., 2014). The British government currently supports Montserrat's economy through the Department for International Development (DFID), providing around $60 \%$ of the recurrent budget (Clay et al., 1999; Sword-Daniels, 2014).

Despite the relocation, resettlement in the north of the island does not prevent the population from being affected by volcanic hazards. Although further from the volcano and largely removed from and potential high-impact hazards such as pyroclastic flows, the population is still intermittently exposed to ashfalls, gases and acid rain. These hazards are relatively low impact but are geographically widespread and extend beyond the boundaries of the exclusion zone. This constitutes an environment of extensive volcanic risk, where such hazards affect populated areas and cause disruptions to many different essential services upon which society depends (Sword-Daniels et al., 2014). 


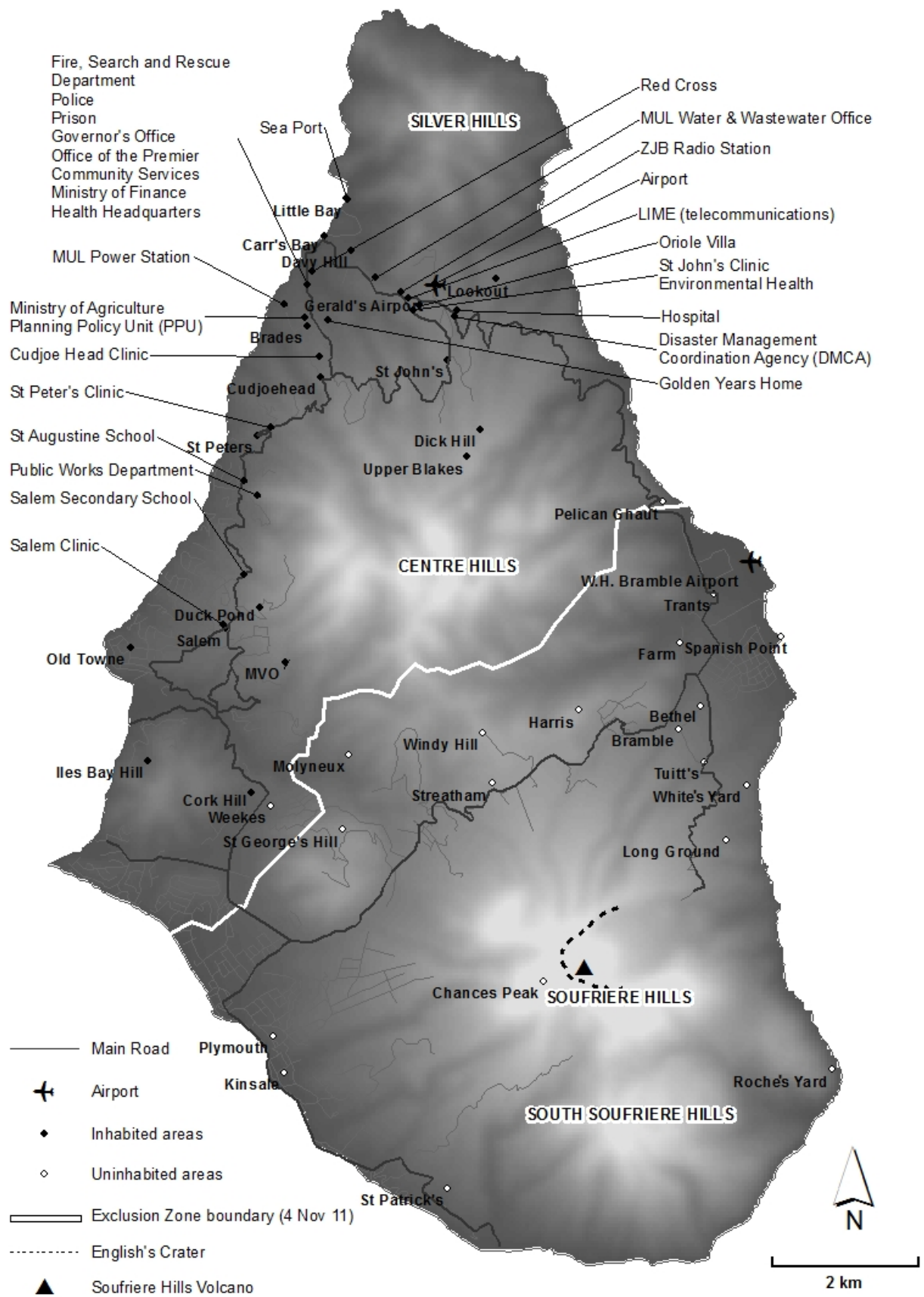

Figure 1. Map of Montserrat, showing the exclusion zone (Montserrat Volcano Observatory, 2014), village and essential service locations in 2012.

Montserrat provides a case study of essential services operating under conditions of extensive volcanic risk. This context allows in-depth exploration of the dynamics and interdependence of essential services under intermittent ashfall hazard conditions, where the interconnected network of essential services are bounded by the geographic extent of the island.

\section{Methodology}

This study is centred on the healthcare system as a critical and complex system with key roles in disaster response as well as the long-term well-being of society (Achour and Price, 2010). Disruption of the healthcare system has a direct impact on the community. The healthcare system is nested within a wider network of interconnected sectors with which it interacts. These sectors are interdependent: drawing on the 
resources of one another in order to provide the services that support urban living.

In this study, a systems thinking approach is taken, which provides a flexible and dynamic framework that allows a problem to be explored holistically (Checkland, 1999). Systems are conceptualised as interacting elements, which work together to produce emergent properties that characterise the system: the whole is greater than the sum of its parts (Meadows, 2009; Checkland, 1999; Simonovic, 2011). A systems approach allows the nature and dynamics of a network of essential services in a chronic volcanic ashfall environment to be understood by focusing on the interactions between sectors (their interrelationships). The interactions are not only within the system itself (the interrelated elements of its construction), but also between the system and its context, consequently the boundaries of the study need to be defined.

Essential services are complex adaptive systems, where the dynamic relationships between elements in each system (infrastructure sector) are self-learning and lead to emergent behaviours, consequently they respond to change nonlinearly (Checkland, 1999; Kay, 2008b; Simonovic, 2011). The ways in which a network of complex adaptive systems interact, and the self-organising behaviour that emerges through their dynamic interrelationships and feedback loops is complex. The state of complex adaptive systems is a function of their history and they evolve over time. Behaviour prediction is not possible with such systems (Kay, 2008a).

In Montserrat the healthcare system consists of one hospital (secondary care), two elderly care homes (one public, one private), four clinics (primary care) and a headquarters. Interactions between the healthcare system, and the supporting network of essential services on the island, forms a bounded sample of system of systems (SoS) that are included in this study. Detailed consideration of interactions with wider society and the general public are not included within the scope and boundaries of this study.

Systems are hierarchical: each level of hierarchy is more complex than the level below and is defined by its emergent properties (Checkland, 1999). Essential services in Montserrat are considered in a hierarchy, where each level of the hierarchy is more complex and consequently data capture is less complete (Waltner-Toews et al., 2008). Several hierarchical levels are included within the boundaries of the sample: healthcare; health-connected sectors (sectors that collaborate with the healthcare sector in order to deliver public health services); lifelines and emergency management (LLEM); and the political, economic, social, environmental context (Fig. 2).

\subsection{Methods}

A case study methodology and qualitative methods were used to gather empirical data on the interrelationships between essential service sectors in Montserrat. Methods included semi-structured interviews, focus groups, and transect

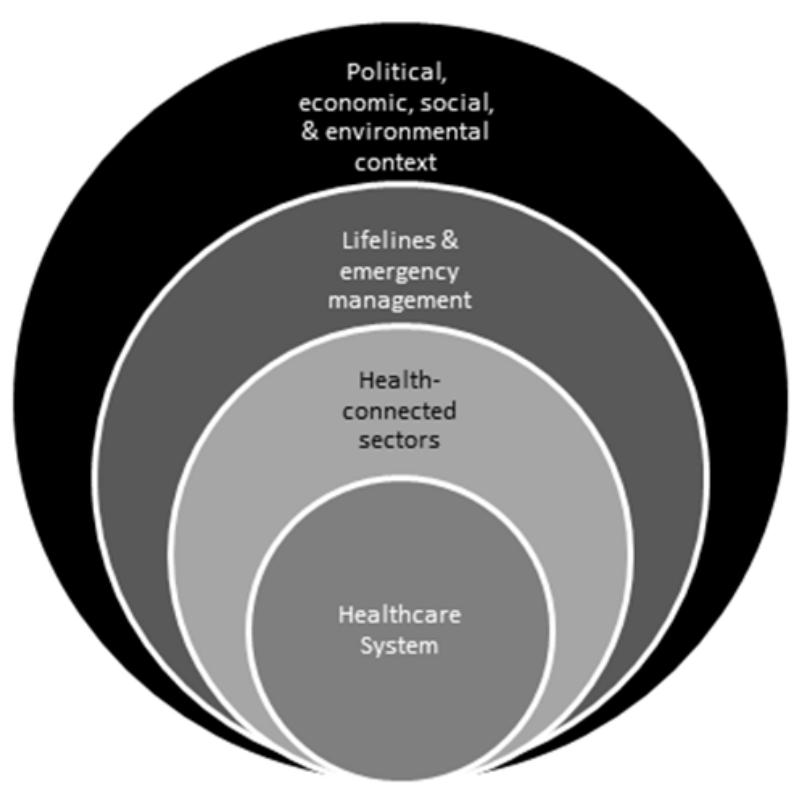

Figure 2. Defined levels of hierarchy, centred on the healthcare system, with increasing in complexity at each level beyond the healthcare system.

walks, as well as secondary data sources (McCracken, 1988; Sarantakos, 2005; Chambers, 1994). The methods were chosen to elicit in-depth descriptive data of how essential services function within the volcanic context, and explored topics including the following: consequences of volcanic activity, responses to activity and ways of reducing the effects, and the sectors with which each essential service sector works, both in the presence and absence of volcanic activity. Wider discussions also included the benefits and challenges of working alongside volcanic hazards and the outlook and wants and needs for the future. Each topic prompted different perspectives on how each essential service functions in Montserrat.

Semi-structured interviews allowed an experienced (longserving) member of each essential service sector to discuss each topic freely, and for the researcher to tailor the interview as relevant issues emerged during discussion. This allowed rich data to be gathered from the perspective of an expert informant. Focus groups allowed interactive engagement of a group of expert informants as they discussed the topic. Following discussion of the topic, this provided an opportunity for facilitator-led discussion explicitly of relationships between sectors: listing the essential service sectors with which their department worked. This promoted a discussion of many different relationships across essential service sectors on the island, and detailed description of the role or purpose of the working relationships between each sector. Relationships that exist during times of low volcanic activity were explicitly sought, as well as relationships that exist during heightened volcanic activity. This structure was 
adopted to elicit data about everyday relationships, as well as those that are perhaps more obvious during times of crisis and therefore may be preferentially recalled or described. Yet although this approach minimises a potential reporting bias during data collection, some implicit relationships may not be fully represented within the data. Finally, two transect walks were conducted, which allowed essential service staff to show the researcher around each facility in a more informal, demonstrative and explanatory way than gained through interview and focus group methods.

This array of methods formed part of a wider study of the resilience of the healthcare system (Sword-Daniels, 2014), with each method and each stage of data collection engaging the participants in a different way, and under different hazard conditions (e.g. during intermittent ashfalls and during quiescence). The design allowed triangulation of methods to cross-check the findings of different data types.

In each method of data collection, discussion of the existence, and description of the nature of the working relationship(s) between sectors was sought explicitly to derive understanding of the ways in which essential services communicate, collaborate and share resources. This constitutes "relationship data", where each identified connection (relationship) is associated with information about which sector the connection comes from and to (the direction of resource flow), along with a description of the purpose or role of the connection, and whether the relationship is reciprocal or one way (unidirectional). This provided detailed descriptions of the interrelationships between essential service sectors. Additional connections between sectors were derived from secondary data documents, and the structure of GoM departments within overarching Ministries (Disaster Management Coordination Agency, 2011; Ministry of Health, 2008; GoM, 2014). Further additions to the data included common-sense relationships (i.e. reliance on water or power) and knowledge of the context (e.g. the Disaster Management Coordination Agency (DMCA) coordinates all departments in emergencies, and ZJB Radio is the national platform for hazard communication in Montserrat). This augments the data collected from qualitative interview and focus group methods.

Data were collected and validated in three stages. The first stage of data collection was conducted between 27 February and 12 March 2010 and involved 14 semi-structured interviews and one transect walk with 11 essential service sectors on the island (Table 1). This stage revealed a number of connections between essential service sectors on Montserrat. Other sectors not included in the first stage of fieldwork, but identified as being connected to a sector included in this initial sample, or identified from the literature, were included in the second stage of fieldwork to further explore the network of connected sectors. This is known as "snowball sampling" (Knoke and Kuklinski, 1982). The second stage of fieldwork was conducted from 4 October to 6 December 2011 and included four focus groups with healthcare staff, a further transect walk and semi-structured interviews. Relationships with sectors included in the first stage of fieldwork, and with others included in the sample for the second stage of fieldwork, were explicitly sought for validation and to gain further detailed description about the relationship(s). A third stage of fieldwork conducted from 27 September to 3 October 2012 sought participant feedback based-on initial results, also known as respondent validation (Bryman, 2012), this further validated the relationship data. One further essential service sector was also able to be included at this time, as they were unavailable during previous stages of data collection (Table 1).

In all data collection stages a total of 23 semi-structured interviews were conducted with healthcare staff, and 29 interviews with 22 other essential services included in the sample. Table 1 shows the sampled sectors and their hierarchical level (with relationship data completeness indicated). Participant data is shown in Table 2. High female representation reflects the composition of healthcare workers on the island (for example, all clinic staff are female).

\section{Results}

To analyse the relationship data, an explanatory diagram of the connections between sectors was created. Drawing on a social network tool for graphical analysis, a digraph (Knoke and Yang, 2008) was constructed from the relationship data, which shows the direction of relationships between nodes in the network. Each essential service sector is represented by a node, and links are drawn between two connected sectors. Arrows point in the direction of resource flow between the sectors. This creates a complex picture of interdependence on Montserrat. Some relationships are documented with sectors that are not included in the sample but are represented on the digraph for completeness (Fig. 3). Relationships change over time and any study of complex adaptive systems provides a static view of a dynamic system, and as such data are limited in their accuracy over time. Yet study of such interrelationships allows understanding of their dynamic behaviour, and of whether their connectedness lends vulnerabilities or capacities to the network as a whole.

The diagraph conveys the complexity of relationships between essential services in Montserrat, but a new approach was required that allowed the dynamics of a network of interconnected systems to be analysed for further explanatory power. To enable further analysis, drawing on existing classification systems in the CIS literature, categories were developed from the empirical data as thematic relationship types. These empirical categories form a new classification of interdependent relationship types, in order to analyse the dynamics of a network of complex systems. 
Table 1. Sectors included in the sample and their hierarchical level. Italics are used to indicate incomplete relationship data capture. The stage at which data were collected from each sector is also shown.

\begin{tabular}{lll}
\hline Essential service sectors included in the sample & Hierarchy level & $\begin{array}{l}\text { Stage of fieldwork } \\
\text { when data were collected }\end{array}$ \\
\hline Healthcare (primary, secondary and headquarters) & Healthcare & 1,2 \\
Community Services & Health-connected & 2 \\
Montserrat Red Cross & Health-connected & 2 \\
Environmental Health & Health-connected & 2 \\
Golden Years Home (private elderly care home) & Health-connected & 2 \\
Prison & Health-connected & 2 \\
Montserrat Utilities Limited (MUL) Power & LLEM & 1,2 \\
Montserrat Utilities Limited (MUL) Water & LLEM & 1,2 \\
LIME (telecommunications) & LLEM & 3 \\
ZJB Radio & LLEM & 1 \\
Airport & LLEM & 2 \\
Fire Search and Rescue (SAR) & LLEM & 1,2 \\
Police & LLEM & 2 \\
Disaster Management Coordination Agency (DMCA) & LLEM & 1,2 \\
Montserrat Volcano Observatory (MVO) & LLEM & 1 \\
Planning policy unit (PPU) & LLEM & 2 \\
Public Works Department (PWD) & LLEM & 1,2 \\
Sea port & LLEM & 2 \\
Ministry of Finance & Context & 2 \\
Governor's Office & Context & 1,2 \\
Education (schools) & Context & 1 \\
Agriculture & Context & 1 \\
\hline
\end{tabular}

Table 2. Participant demographic information relevant to this study.

\begin{tabular}{|c|c|c|c|c|c|c|c|}
\hline & $\begin{array}{c}\text { No. of } \\
\text { participants }\end{array}$ & Male & Female & $\begin{array}{c}\text { No. living } \\
\text { on Montserrat } \\
\text { pre-1995 }\end{array}$ & $\begin{array}{l}\text { No. moved } \\
\text { to Montserrat } \\
\text { after } 1995\end{array}$ & Montserratian & Non-Montserratian \\
\hline Focus group participants & 28 & 1 & 27 & $12(43 \%)$ & $16(57 \%)$ & 17 & 11 \\
\hline Transect walk participants & 2 & 2 & 0 & 1 & 1 & 1 & 1 \\
\hline
\end{tabular}

a Four focus group participants were additionally interviewed, and are subtracted from the final totals to avoid double-counting.

${ }^{\mathrm{b}}$ One participant of unknown nationality was included as non-Montserratian.

\subsection{Developing a classification system for analysis}

Several classifications of interdependence types exist in the CIS literature (Rinaldi et al., 2001; Dudenhoeffer et al., 2006; Wallace and Wallace, 2008; Eusgeld et al., 2011; Pederson et al., 2006). Of these a comprehensive and widely used system is that of Rinaldi et al. (2001), which defines the following types of interdependencies: physical, cyber, logical, and geographic. This classification system is modified for use in Montserrat, drawing on other classifications and tailoring these to the context. The "geographic" category is not used for analysis in this context as all systems are located within close geographic proximity to each other. "Cyber" connec- tions result from automated infrastructure control systems, which are not widely present in Montserrat and therefore not used. "Logical" refers to any other connection and is considered too general for use here. Additionally, a "societal" category is used by Pederson et al. (2006) to describe the influence that one service may have on societal factors such as public opinion, public confidence, or cultural issues that cause an effect in another infrastructure. However, this study is bounded by a focus on essential services and therefore does not include the general public. The impact on society therefore cannot be included here, which is a limitation of this study. Yet within the essential services data relationships are identified that perform specific social functions (for the 


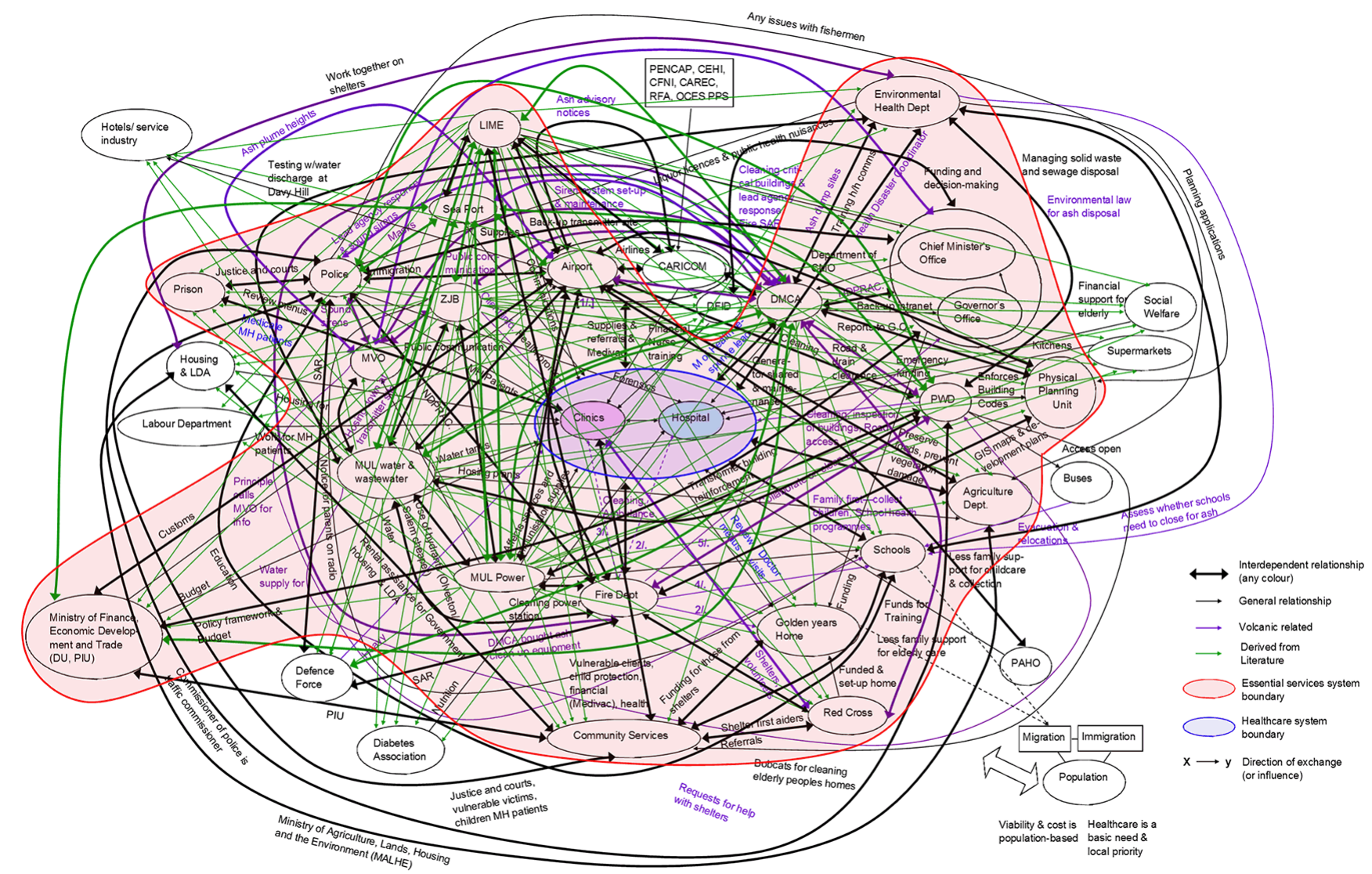

Figure 3. Digraph of relationships between essential services in Montserrat. Centred on the healthcare system, the boundary of the sample is delineated. Black arrows indicate general relationships, purple arrows indicate volcanic relationships, and green arrows are those identified from secondary sources.

greater social good). These are therefore included as a modified 'social' category within this context.

Empirical data was used to develop relevant categories for analysis within the Montserrat context. The new classification system developed for use in this study is as follows:

- physical - infrastructure systems linked through their material outputs (i.e. power, water) (Rinaldi et al., 2001). This includes physical resources;

- information - linked through the transmission of information (broadcasting, and other communication mechanisms for disaster coordination);

- organisational - linkages created through collaborations, working relationships or technical advice, or linkages through an overarching government ministry;

- financial - transfer of finances, funding, or any other economic transaction between essential services;

- social - collaborations or shared resources specifically to care for those in need (e.g. care of elderly and mental healthcare clients) as well as the role of individuals who create links with other sectors.
These classification types are then further categorised by hazard conditions for more detailed analysis in an extensive risk context. Volcanic and general relationships are differentiated in order to explore dynamic changes in relationships with changing levels of volcanic activity. Yet in this ongoing eruption context relationships that are evident during low volcanic activity may have an implicit function when volcanic activity increases: general relationships may not be wholly independent from the volcanic context. However, the distinction between these two typologies provides a useful framework for analysis of those relationships that are active during low volcanic activity, and those that emerge or become visible during heightened volcanic activity. These two types are therefore differentiated as those that are active (or visible) under each of these hazard conditions. Volcanic refers to relationships that become active (or are visible) during heightened volcanic activity; general refers to relationships that are active in the absence of volcanic activity. For example, general relationships may include the following:

- physical - provision of basic lifeline services, telecommunications and supplies; 
- organisational - responsibilities for maintenance, working collaborations, technical advice;

- information - communication of general service messages via ZJB Radio to the public;

- financial - budgetary relationships;

- social - social needs e.g. the welfare system, employment and housing.

Volcanic relationships may include the following:

- physical - physical resources and equipment for ashfall clean-up;

- organisational - responsibilities for ashfall clean-up and shelter management, or emergency response training;

- information - hazard communication (warnings and alerts);

- financial - emergency financial relationships;

- social - voluntary cleaning of ash from vulnerable sectors.

Subdivision of relationships into type (physical, organisational, information, financial, social) and condition (volcanic and general) allows detailed analysis of the multiple ways in which infrastructure sectors may be connected, and under which hazard conditions they interact. This allows detailed analysis of interdependence in an extensive risk environment. The following section analyses the relationship data using this new classification system, in order to explore the dynamics of infrastructure interdependence in the presence and absence of ashfall hazards.

\subsection{Dynamic relationships}

Between all 22 sectors explored in this analysis, there are a total of 331 relationships identified across the network. The classification of relationships by type for the whole network is shown in Table 3. Overall, the contribution of organisational relationship types is the largest, at $46 \%$ of all relationships. Physical relationships account for $26 \%$ - a quarter of all connections. Information relationships account for $17 \%$ of the overall relationships, and Financial and Social categories form the remaining $11 \%$ of connections across the network.

Of the total of 331 individual connections between the 22 essential services sectors in Montserrat, 235 pre-exist in the absence of volcanic activity, and are classed as general relationships. The essential services in Montserrat are seen to be highly interconnected. During heightened volcanic activity, an additional 96 relationships are formed between the essential service sectors in the network, an increase of $41 \%$ in the total number of relationships.
Table 3. The total number of relationships across all of the essential services included in the sample, and their classification type.

\begin{tabular}{lcc}
\hline $\begin{array}{l}\text { Type of } \\
\text { relationship }\end{array}$ & $\begin{array}{c}\text { Total no. of } \\
\text { relationships } \\
\text { of each type }\end{array}$ & $\begin{array}{c}\text { \% of } \\
\text { relationships } \\
\text { of each type }\end{array}$ \\
\hline Physical & 86 & 26 \\
Organisational & 152 & 46 \\
Information & 56 & 17 \\
Financial & 28 & 8 \\
Social & 9 & 3 \\
\hline Total & 331 & 100 \\
\hline
\end{tabular}

The number of relationships received by each sector from the network of essential services is disaggregated by condition into general and volcanic relationships in Table 4. There is no clear correlation between sectors that have higher numbers of general relationships and the number of volcanic relationships that form in response to heightened activity.

Sectors are connected if there is at least one tie between any two sectors. There are a total of 132 pairs of connected sectors in this network during low volcanic activity (general relationships), of a possible 462 , if every sector had a connection to every other. The nature of relationship transformations varies: some pairs of sectors adapt pre-existing general relationships during heightened volcanic activity, and some new connections form between previously unconnected sectors. In this way, relationships between sectors may dynamically change in response to hazard events.

During volcanic activity, 17 pairs of connected sectors are seen to adapt their pre-existing relationship(s) to include at least one volcanic relationship (13\%). For example the DMCA owns and maintains the generator that it shares with the hospital. This is a general relationship. However, in a volcanic emergency the hospital takes the lead agency response role for mass casualty situations, supported by the DMCA. This is a volcanic relationship. In another example, both MUL Water and MUL Power provide the general power and water supply around the island, including to the ZJB radio station facility. However, during heightened volcanic activity the nature of the relationships between the sectors changes, and MUL Water and MUL Power rely on ZJB Radio to provide hazard information, and to communicate water advisory notices or power outage notices to the public. Additionally MUL Water will hose down the radio transmitter site on Silver Hills (Fig. 1) to clear it of ash for ZJB Radio. These are dynamic shifts in interrelationships between periods of low or heightened volcanic activity.

In other cases, new relationships are formed between sectors. A total of 39 newly connected pairs of sectors are created: spontaneously linking previously unconnected pairs. For example, Environmental Health is called-in to assess whether schools need to close due to ashfall, and Commu- 
Table 4. The total number of relationships received by each sector from the network of essential services, disaggregated by relationship condition (volcanic and general). Italics are used to indicate incomplete relationship data capture.

\begin{tabular}{lccc}
\hline Infrastructure sector & $\begin{array}{c}\text { No. of general } \\
\text { relationships }\end{array}$ & $\begin{array}{c}\text { No. of volcanic } \\
\text { relationships }\end{array}$ & $\begin{array}{c}\text { Sum of all } \\
\text { relationships }\end{array}$ \\
\hline Healthcare & 31 & 11 & 42 \\
Airport & 16 & 6 & 22 \\
Montserrat Utilities Limited (MUL) Water & 15 & 3 & 18 \\
Community Services & 13 & 4 & 17 \\
Police & 13 & 6 & 19 \\
Sea Port & 13 & 1 & 13 \\
Environmental Health & 12 & 3 & 15 \\
Fire Search and Rescue (SAR) & 12 & 3 & 15 \\
Public Works Department (PWD) & 11 & 6 & 17 \\
Education (schools) & 10 & 5 & 15 \\
Montserrat Utilities Limited (MUL) Power & 10 & 3 & 13 \\
Planning policy unit (PPU) & 10 & 1 & 11 \\
Agriculture Department & 9 & 1 & 10 \\
Golden Years Home & 9 & 2 & 11 \\
Governor's Office & 8 & 3 & 11 \\
Ministry of Finance & 8 & 1 & 9 \\
Prison & 8 & 1 & 9 \\
Disaster Management Coordination Agency (DMCA) & 6 & 23 & 29 \\
LIME (telecommunications) & 6 & 4 & 10 \\
Montserrat Volcano Observatory (MVO) & 6 & 5 & 11 \\
Montserrat Red Cross & 6 & 2 & 8 \\
ZJB Radio & 4 & 2 & 6 \\
\hline Total & 236 & 96 & 331 \\
\hline
\end{tabular}

Table 5. The total number of general and volcanic relationships across the essential service sectors, classified by type.

\begin{tabular}{lcccc}
\hline $\begin{array}{l}\text { Type of } \\
\text { relationship }\end{array}$ & $\begin{array}{c}\text { No. volcanic } \\
\text { relationships }\end{array}$ & $\begin{array}{c}\text { \% of each type of } \\
\text { volcanic relationship }\end{array}$ & $\begin{array}{c}\text { No. general } \\
\text { relationships }\end{array}$ & $\begin{array}{c}\text { \% of each type of } \\
\text { general relationships }\end{array}$ \\
\hline Physical & 10 & 10 & 76 & 32 \\
Organisational & 44 & 46 & 108 & 46 \\
Information & 33 & 34 & 23 & 10 \\
Financial & 2 & 2 & 26 & 11 \\
Social & 7 & 7 & 2 & 1 \\
\hline Total & 96 & $99^{\mathrm{a}}$ & 235 & 100 \\
\hline
\end{tabular}

a does not sum to $100 \%$ due to rounding.

nity Services may also request help with the shelters from Environmental Health. Neither of these relationships were enacted (or functionally active) during low volcanic activity. In other examples, the police take on additional responsibilities during volcanic activity. These include enforcing access restrictions to the exclusion zone when the hazard level changes, and also sounding the southern evacuation sirens from Salem Police Station in emergencies, in response to MVO's advice.

During volcanic activity, the total number of connected pairs in the network increases from 132 to 171 . Of these, a total of 56 pairs have at least one volcanic relationship (33\% of connected pairs).

Further exploring the types of relationships that exist in pre-stressed (general) and stressed (volcanic) states reveals that different types of relationship are enacted under different environmental conditions. Table 5 shows the number of volcanic and general relationships within each classified relationship type.

For general relationships, organisational and physical relationship types contribute the most to the total number of connections across the network. However, the relationships 
that form during volcanic activity are dominated by organisational and informational linkages. These volcanic relationships include requests for assistance (e.g. ash clean-up or technical assessments), emergency roles and finances, and hazard communication. For example LIME (telecommunications) sends SMS blasts to the DMCA for hazard communication, and ZJB Radio broadcasts hazard updates to the public. The fire department are paid by LIME to clean ash blockages, and the Ministry of Finance provides financial support for emergency response actions. Relationships across the network therefore transform in both number and type during heightened volcanic activity.

\section{Discussion}

The results of this study show that essential services on Montserrat have many connections between them, and that their complex relationships have a range of types: social, physical, financial, organisational, and informational. Subdivision of relationships into this new classification of interdependence types and condition (volcanic and general) allows detailed analysis of the multiple ways in which infrastructure sectors may be connected, and under what hazard conditions they interact. This provides a unique perspective on infrastructure interdependence in an extensive risk context.

Many of the relationships between essential services in Montserrat could not be detected from literature, or derived from logical physical or organisational connections between systems. A context-specific view of interrelationships is necessary to be able to understand the complexity and variety of interdependencies between essential services. In Montserrat, physical relationships between essential services account for only a quarter of all relationships across the network. This is equalled by contributions of financial, information and social linkages, each of which are largely unique to the context. Organisational linkages form the predominant type of connection between sectors. Models of interdependent systems, and impact studies using secondary data cannot capture this complexity: accounting for this diversity in interdependent relationship types, which defines the nature of a complex network.

In Montserrat, during increased volcanic activity, relationships transform in their type and their function, increasing communication and information sharing by augmenting and adapting network relationships. The unique context of extensive risk on a small island is likely to play a role in fostering such linkages. Yet the adaptive behaviour of systems has been observed in the United States, albeit in response to a single disaster event (Kartez, 1984). In Montserrat relationships have been enacted many times over the course of the long-duration eruption. In this context, the lack of correlation between sectors with high numbers of general relationships and the formation of emergent volcanic relationships, demonstrates the dynamic and complex nature of interdependence in response to hazards. Complex and nonlinear behaviour is seen to emerge from this network during periods of heightened stress. The spontaneous formation of links between seemingly unconnected sectors may derive from historic linkages that act as sleeping links, which may not be evident until stressed. Although data gathering is improved by adopting an in-depth qualitative approach, and by explicitly seeking everyday as well as response-based relationships, such sleeping links may remain "invisible" (not fully represented during data collection) until they are enacted. This means that identifying relationships and developing an understanding of the adaptive behaviour of a network is challenging in a pre-disaster context. Improving data capture of these types of links may require in-depth data gathering approaches coupled with detailed exploration of historical events and relationships.

Another important consideration is the relative significance of relationships to the successful function of the network and of society. This study is bounded by a sample of essential services and does not include detailed exploration of interactions with wider society. The interpretation of relationship significance is beyond the scope of this study, yet it is clear that not all relationships contribute equally to improving or disrupting the function of essential services across the network. Some connections are more or less critical, under different circumstances, and at different points in time. For example, for the function of the essential services network in short-term volcanic emergencies, disaster coordination (DMCA), information dissemination (e.g. telecommunications, radio) and lifeline services (e.g. power, water) may be critical to the daily operations of many other facilities. In the longer-term, collaborations between sectors to perform maintenance functions and longer-term operations increases in importance to sustain infrastructure functions. Beyond implications of relationship function for the network of connected sectors, impacts for society are critical considerations. Healthcare performs essential functions in both short-term volcanic emergencies and for the long-term wellbeing of society: disruption of this sector has a direct impact on society. Other sectors may suffer disruption without significant societal impacts during the short-term, such as planning departments or justice and courts. Interpreting differentials in relationship significance across the network requires a detailed analysis of context-specific data in order to understand the consequences of relationship disruption. This reflects a limitation of this study, and is an important avenue for further enquiry. Such reflections on relationship importance should be considered in terms of consequences for each sector, for the network of essential services as a whole, and for wider society.

To identify whether essential service interdependence within the local context contributes to increased vulnerability or increased capacity of systems, the drivers of system behaviour need to be understood. In Montserrat, there are many examples of essential services that apply their core skills to 
respond to emergent needs. Examples of this response behaviour include the following.

- Fire search and rescue (SAR) volunteer to perform the clean-up of ash in vulnerable areas (hospital, schools, clinics, mental healthcare duplexes, government buildings).

- Police assist clinic mental healthcare nurses with finding and medicating patients during volcanic activity, or in emergency shelters.

- Public notices are broadcast on ZJB Radio by each disrupted sector to inform their clients of any service effects.

- Ash advisories are given out on ZJB Radio during particularly active times for public information.

- MUL water fills the water tanks at healthcare facilities during ashfalls (and hurricanes).

- Several sectors work together when the shelters are in use, each with clearly defined roles and responsibilities (Red Cross, environmental health, primary healthcare).

In particular, ashfall clean-up is prioritised for sectors that are considered to be vulnerable, which include the airport, healthcare, geriatric homes and schools. For example, the assessment of whether schools need to close in ashfall (conducted by Environmental Health) was developed as a result of concerns over the effects of ashfalls on children's health. The prioritisation appears to reflect a collective concern for others within Montserrat's society (Sword-Daniels, 2014). These priorities and values affect the behaviour of the essential service network. In Montserrat, vulnerable sectors gain additional capacities from the wider network of essential services during volcanic activity. In other cases, sectors that in advance of a disaster may be identified as likely to be more greatly affected, may therefore be preferentially supported by local mechanisms. However, this adaptive capacity may be unique to this context: the behaviour of the network is dependent on the values of society, which drives the response of essential services.

By taking an in-depth view of the relationships between systems, drawing on the knowledge and experience of many expert participants within the context, a rich picture of essential service interdependence can be developed. Such approaches are time consuming and costly, they require engagement with experienced expert participants across a range of different essential services, and a staged approach to data capture in order to develop an appropriate sample of interconnected sectors within the context. Yet such detailed study allows far greater understanding of the complexity of relationship types, their dynamic interactions in the presence and absence of hazards, and contextual understanding of the behaviour of a whole network of complex adaptive systems.
It is therefore recommended that future studies of essential service interdependence take a more nuanced, interpretive perspective to understanding complex problems, rather than traditional positivist approaches (Cavallo and Ireland, 2014). This will enable better understanding of complexity and dynamic behaviour. A social network study finds that there is no clear correlation between the connectedness of a network and its resilience, and that resilience must be understood and interpreted in context (Janssen et al., 2006). In-depth understanding of each case study can reveal whether interdependencies in each context contribute capacities or vulnerabilities to the essential service network, allowing resilience to be interpreted.

In future studies the classification of relationships by type and condition has multiple uses, from mapping out information and communication flow across a network, to understanding disaster economics. This type of analysis can shed light on the role of individuals or of individual sectors within a network as critical connectors. Further, network analysis could allow the identification of critical nodes within a network: those that enable function of a wide range of other sectors, and those that are supported by resources from many other sectors. This could improve knowledge of how best to increase resilience across a network of interconnected systems within each unique context, accounting for the dynamics and behaviour of the interconnected whole.

\section{Conclusions}

This empirical study explores the interdependence and adaptive behaviour of a network of essential services in Montserrat, West Indies. This study presents a new methodology through which interdependent relationships may be explored, by drawing on in-depth descriptive data and engagement with expert participants. We find that many different types of relationships exist between essential services. In order to understand this complexity, we develop a new classification system for analysis drawing from the literature and empirical data. Relationships are further categorised by hazard conditions (increases and decreases in volcanic activity). This provides a novel framework for exploring the dynamics and complexity of interdependent relationships in an extensive risk environment. Such a framework can be adapted for use in other hazard contexts.

Interdependent essential services are seen to behave nonlinearly, transforming their relationships in both type and number when exposed to hazards. In this context, emergent relationships increase communication and organisational cooperation across the network, adapting to increase the capacities for response. Interdependencies are therefore seen to add capacities to certain prioritised sectors in the network (e.g. healthcare, schools), which increases their resilience.

Further analysis could develop mechanisms for comparing the importance or significance of relationships to the func- 
tion of the network as a whole, as well as to the societies that essential services support. The degree to which each relationship is capable of improving or disrupting social and infrastructure function would require further in-depth and contextspecific study and would be a valuable avenue of enquiry that would add depth to our understanding of interdependent systems.

Future studies of interdependence should account for the diversity of ways in which sectors may interact with each other, beyond considering just physical and organisational linkages, and must account for both the vulnerabilities and the capacities created by interdependence in order to interpret resilience. Further in-depth case studies will increase knowledge of how networks of complex systems may adapt and respond under stress in real-world contexts. This will improve our understanding of the complexity of interdependent systems within each unique context, providing pathways for increasing their resilience.

Acknowledgements. We are indebted to all of the people who participated in this research in Montserrat; both interviewees and others who interacted with the researcher in the field, and who gave generously of their time and contributed to this research. The support of Paul Cole (the director of the Montserrat Volcano Observatory at the time of research), and the rest of the Montserrat Volcano Observatory staff was also invaluable during fieldwork. We would also like to thank John Twigg, Sue Loughlin and David Johnston for intellectual guidance during the research process. We would like to thank EPSRC for funding this research through the Centre for Urban Sustainability and Resilience at University College London, the British Geological Survey BUFI fund for funding the fieldwork to undertake this research and the New Zealand Ministry of Business, Innovation and Employment Natural Hazard Research Platform Grant C05X0804 (TW). We are grateful to the British Geological Survey and the Strengthening Resilience in Volcanic Areas (STREVA) project for support during the writing of this paper. Finally, we would like to thank Carina Fearnley for comments on an early draft of the manuscript, as well as two anonymous referees for their constructive comments, which have improved this paper.

Edited by: U. Ulbrich

Reviewed by: two anonymous referees

\section{References}

Achour, N. and Price, A. D. F.: Resilience strategies of healthcare facilities: present and future, International Journal of Disaster Resilience in the Built Environment, 1, 264-276, 2010.

Allen, T. F. H.: Scale and type: a requirement for addressing complexity with dynamical quality, in: The Ecosystem Approach: Complexity, Uncertainty, and Managing for Sustainability, edited by: Waltner-Toews, D., Kay, J. J., and Lister, N.-M. E., Columbia University Press, New York, 37-49, 2008.

Aspinall, W. P., Loughlin, S. C., Michael, F. V, Miller, A. D., Norton, G. E., Rowley, K. C., Sparks, R. S. J., and Young, S. R.:
The Montserrat Volcano Observatory: its evolution, organisation, role and activities, in: The Eruption of Soufriere Hills Volcano, Montserrat from 1995 to 1999, Memoirs 2002, edited by: Druitt, T. H. and Kokelaar, B. P., Geological Society, London, 71-91, 2002.

Auckland Engineering Lifelines Group: Auckland Engineering Lifelines Project, final report - stage one, Auckland, New Zealand, 1999.

Blong, R. J.: Volcanic Hazards: a Sourcebook on the Effects of Eruptions, Academic Press, Australia, 1-424, 1984.

Bruneau, M., Chang, S., Eguchi, R. T., Lee, G. C., O'Rourke, T. D., Reinhorn, A. M., Shinozuka, M., Tierney, K., Wallace, W. A., and von Winterfeldt, D.: A framework to quantitatively assess and enhance the seismic resilience of communities, Earthq. Spectra, 19, 733-752, 2003.

Bryman, A.: Social Research Methods, Oxford University Press, 2012.

Cavallo, A. and Ireland, V.: Preparing for complex interdependent risks: a system of systems approach to building disaster resilience, International Journal of Disaster Risk Reduction, 9, 181-193, available at: http://linkinghub.elsevier.com/retrieve/pii/ S2212420914000405 (last access: 14 July 2014), 2014.

Chambers, R.: Participatory Rural Appraisal (PRA): analysis of experience, World Dev., 22, 1253-1268, 1994.

Chang, S. E.: Infrastructure resilience to disasters, The Bridge, 39, 36-41, 2009.

Chang, S. E. and Shinozuka, M.: Measuring improvements in the disaster resilience of communities, Earthq. Spectra, 20, 739-755, doi:10.1193/1.1775796, 2004

Chang, S. E., McDaniels, T. L., Mikawoz, J., and Peterson, K.: Infrastructure failure interdependencies in extreme events: power outage consequences in the 1998 ice storm, Nat. Hazards, 41, 337-358, 2007.

Checkland, P.: Systems Thinking, Systems Practice, John Wiley and Sons, West Sussex, England, 1999.

Clay, E., Barrow, C., Benson, C., Dempster, J., Kokelaar, P., Pillai, N., and Seaman, J.: An Evaluation of HMG's Response to the Montserrat Volcanic Emergency, Volume 1, Department for International Development, London, UK, 1999.

Disaster Management Coordination Agency: Evacuation Plan for Residents from Isles Bay to Nantes River: Officials Guide, St John's, Montserrat, 2011.

Druitt, T. H. and Kokelaar, B. P.: The eruption of Soufriere Hills Volcano, Montserrat, from 1995 to 1999, in: The Eruption of Soufriere Hills Volcano, Montserrat from 1995 to 1999, Memoirs 2002, Geological Society, London, 2002.

Dudenhoeffer, D. D., Permann, M. R., and Boring, R. L.: Decision consequence in complex environments: visualising decision impact, in: Proceeding of Sharing Solutions for Emergencies and Hazardous Environments, 11-16 February 2006, Salt Lake City, Utah, 211-218, 2006.

Eusgeld, I., Nan, C., and Dietz, S.: "System-of-systems" approach for interdependent critical infrastructures, Reliab. Eng. Syst. Safe., 96, 679-686, available at: http://linkinghub.elsevier. com/retrieve/pii/S0951832010002668 (last access: 3 June 2013), 2011.

Government of Montserrat (GoM): Government of Montserrat, available at: www.gov.ms (last access: 16 July 2014), 2014. 
Haynes, K.: Exploring the communication of risk during a volcanic crisis: a case study of Montserrat, University of East Anglia, WI, 2005.

Haynes, K.: Volcanic island in crisis: investigating environmental uncertainty and the complexities it brings, The Australian Journal of Emergency Management, 21, 21-28, 2006.

Janssen, M. A., Bodin, Ö., Anderies, J. M., Elmqvist, T., Ernstson, H., Mcallister, R. R. J., Olsson, P., and Ryan, P.: Toward a network perspective of the study of resilience in social-ecological systems, Ecol. Soc., 11, 15, 20 pp., 2006.

Johnston, D. M.: The Impacts of Recent Falls of Volcanic Ash on Public Utilities in two Communities in the United States of America, in: Physical and Social Impacts of past and future volcanic eruptions in New Zealand, Massey University, Palmerston North, New Zealand, 426 pp., 1997.

Johnston, D. M., Houghton, B. F., Neall, V. E., Ronan, K. R., and Paton, D.: Impacts of the 1945 and 1995-96 Ruapehu eruptions, New Zealand: an example of increasing societal vulnerability, Geol. Soc. Am. Bull., 112, 720-726, 2000.

Johnston, D. M., Stewart, C., Leonard, G. S., Hoverd, J., Thordarsson, T., and Cronin, S.: Impacts of volcanic ash on water supplies in Auckland: Part I, Institute of Geological and Nuclear Sciences, Lower Hutt, New Zealand, 2004.

Kartez, J. D.: Crisis response planning: toward a contingent analysis, J. Am. Plann. Assoc., 50, 9-21, 1984.

Kay, J. J.: An introduction to systems thinking, in: The Ecosystem Approach: Complexity, Uncertainty, and Managing for Sustainability, edited by: Waltner-Toews, D., Kay, J. J., and Lister, N.M. E., Columbia University Press, New York, 3-13, 2008a.

Kay, J. J.: Framing the situation: developing a system description, in: The Ecosystem Approach: Complexity, Uncertainty, and Managing for Sustainability, edited by: Waltner-Toews, D., Kay, J. J., and Lister, N.-M. E., Columbia University Press, New York, 15-34, 2008b.

Knoke, D. and Kuklinski, J. H.: Network Analysis, Sage, California, 1982.

Knoke, D. and Yang, S.: Social Network Analysis, SAGE Publications, London, UK, 2008.

Leonard, G. S., Johnston, D. M., Williams, S., Cole, J. W., Finnis, K., and Barnard, S.: Impacts and Management of Recent Volcanic Eruptions in Ecuador: Lessons for New Zealand, Institute of Geological and Nuclear Sciences, Wellington, New Zealand, 2005.

McCracken, G.: The Long Interview: Qualitative Research Methods, SAGE Publications Inc, California, USA, 1988.

McDaniels, T., Chang, S., Cole, D., Mikawoz, J., and Longstaff, H.: Fostering resilience to extreme events within infrastructure systems: characterizing decision contexts for mitigation and adaptation, Global Environ. Chang., 18, 310-318, available at: http: //linkinghub.elsevier.com/retrieve/pii/S0959378008000174, last access: 28 May 2013, 2008.

Meadows, D. H.: Thinking in Systems: a Primer, Earthscan, London, 2009.

Ministry of Health: Cascade for Mass Casualty Plan, Ministry of Health, Brades, Montserrat, 2008.

Montserrat Volcano Observatory: Montserrat Volcano Observatory (MVO), available at: www.mvo.ms (last access: 12 November 2014), 2014.
Oh, E. H., Deshmukh, A., and Hastak, M.: Disaster impact analysis based on inter-relationship of critical infrastructure and associated industries: a winter flood disaster event, International Journal of Disaster Resilience in the Built Environment, 1, 25-49, 2010.

O'Rourke, T. D.: Critical infrastructure, interdependencies and resilience, The Bridge, 37, 22-29, 2007.

Pederson, P., Dudenhoeffer, D., Hartley, S., and Permann, M.: Critical Infrastructure Interdependency Modeling: a Survey of US and International Research, Idaho National Laboratory (INL), Idaho Falls, USA, 2006.

Pelling, M.: Assessing urban vulnerability and social adaptation to risk: evidence from Santo Domingo, Int. Dev. Plann. Rev., 24, 59-76, 2002.

Platt, R. H.: Lifelines: an emergency management priority for the United States in the 1990s, Disasters, 15, 172-176, 1991.

Reed, D. A., Kapur, K. C., and Christie, R. D.: Methodology for assessing the resilience of networked infrastructure, IEEE Systems Journal, 3, 174-180, 2009.

Rinaldi, S. M., Peerenboom, J. P., and Kelly, T. K.: Identifying, understanding, and analyzing critical infrastructure interdependencies, Control Systems, 21, 11-25, 2001.

Ronan, K. R., Paton, D., Johnston, D. M., and Houghton, B. F.: Managing societal uncertainty in volcanic hazards: a multidisciplinary approach, Disaster Prevention and Management, 9, 339349, 2000.

Santella, N., Steinberg, L. J., and Parks, K.: Decision making for extreme events: modeling critical infrastructure interdependencies to aid mitigation and response planning, Review of Policy Research, 26, 409-422, doi:10.1111/j.1541-1338.2009.00392.x, 2009.

Sarantakos, S.: Social Research, Palgrave Macmillan, Basingstoke, Hampshire, UK, 2005.

Simonovic, S. P.: Systems Approach to Management of Disasters: methods and applications, John Wiley and Sons, Hoboken, New Jersey, 2011.

Sparks, R. S. J. and Young, S. R.: The eruption of Soufriere Hills Volcano, Montserrat (1995-1999): overview of scientific results, in: The Eruption of Soufriere Hills Volcano, Montserrat from 1995 to 1999, Memoirs 2002, Geological Society, London, 4569, 2002.

Stewart, C., Johnston, D. M., Leonard, G. S., Horwell, C. J., Thordarson, T., and Cronin, S. J.: Contamination of water supplies by volcanic ashfall: a literature review and simple impact modelling, J. Volcanol. Geoth. Res., 158, 296-306, 2006.

Sword-Daniels, V. L.: Exploring the consequences and dynamics of long-term volcanic activity for the healthcare system in Montserrat, West Indies, University College London, 2014.

Sword-Daniels, V. L., Wardman, J., Stewart, C., Wilson, T. M., Johnston, D., and Rossetto, T.: Infrastructure Impacts, Management and Adaptations to Eruptions at Volcán Tungurahua, Ecuador, 1999-2010, GNS Science, New Zealand, Lower Hutt, New Zealand, 2011.

Sword-Daniels, V. L., Wilson, T. M., Sargeant, S., Rossetto, T., Twigg, J., Johnston, D. M., Loughlin, S. C., and Cole, P. D.: Consequences of long-term volcanic activity for essential services in Montserrat: challenges, adaptations and resilience, in: The Eruption of Soufriere Hills Volcano, Montserrat from 2000 to 2010, 
edited by: Wadge, G., Robertson, R. E. A., and Voight, B., Geological Society of London Memoirs, London, 471-488, 2014.

Tobin, G. A. and Whiteford, L. M.: Chronic hazards: health impacts associated with on-going ash-falls around Mt. Tungurahua in Ecuador, Papers of the Applied Geography Conferences, 8493, 2004.

United Nations International Strategy for Disaster Reduction: International Strategy for Disaster Reduction (ISDR): Global Assessment Report on Disaster Risk Reduction, United Nations, Geneva, Switzerland, 2009a.

United Nations International Strategy for Disaster Reduction: International Strategy for Disaster Reduction (ISDR): Terminology on Disaster Risk Reduction, United Nations, Geneva, Switzerland, 2009b.

United Nations International Strategy for Disaster Reduction: International Strategy for Disaster Reduction (ISDR): Global Assessment Report on Disaster Risk Reduction, United Nations, Geneva, Switzerland, 2013.

Wallace, D. and Wallace, R.: Urban systems during disasters: factors for resilience, Ecol. Soc., 13, 18, 14 pp., 2008.

Waltner-Toews, D., Kay, J. J., and Lister, N.-M. E.: The Ecosystem Approach: Complexity, Uncertainty, and Managing for Sustainability, Columbia University Press, New York, 2008.
Wardman, J., Sword-Daniels, V., Stewart, C., and Wilson, T.: Impact Assessment of the May 2010 Eruption of Pacaya Volcano, Guatemala, GNS Science, New Zealand, Lower Hutt, New Zealand, 2012.

Wilson, T. M., Daly, M., and Johnston, D.: Review of Impacts of Volcanic Ash on Electricity Distribution Systems, Broadcasting and Communication Networks, Auckland Regional Council Technical Publication, Auckland Engineering Lifelines Group, Auckland, New Zealand, 2009.

Wilson, T. M., Stewart, C., Cole, J. W., Johnston, D. M., and Cronin, S. J.: Vulnerability of farm water supplies to volcanic ash fall, Environmental Earth Sciences, 61, 675-688, 2010.

Wilson, T. M., Cole, J. W., Stewart, C., Cronin, S. J., and Johnston, D. M.: Ash storms: impacts of wind-remobilised volcanic ash on rural communities and agriculture following the 1991 Hudson eruption, southern Patagonia, Chile, B. Volcanol., 73, 223-239, 2011.

Wilson, T. M., Stewart, C., Sword-Daniels, V., Leonard, G. S., Johnston, D. M., Cole, J. W., Wardman, J., Wilson, G., and Barnard, S. T.: Volcanic ash impacts on critical infrastructure, Phys. Chem. Earth, 45-46, 5-23, 2012.

Wisner, B., Blaikie, P., Cannon, T., and Davis, I.: At Risk: natural hazards, people's vulnerability and disasters, 2nd Edn., Routledge, London, 2004. 